\title{
Emergent Volatility in Asset Markets with Heterogeneous Agents
}

\author{
HONGGANG LI ${ }^{\mathrm{a}, *}$ and J. BARKLEY ROSSER JR. ${ }^{\mathrm{b}, \dagger}$ \\ ${ }^{\mathrm{a}}$ School of Management, Beijing Normal University, Beijing 100875, China; ${ }^{\mathrm{b}}$ Program in Economics MSC 0204, \\ James Madison University, Harrisonburg, VA 22807, USA
}

(Received 30 June 2000)

\begin{abstract}
This paper examines the emergence of complex volatility in dynamic asset markets when there are heterogeneous agents. A discrete formulation is studied with two categories of market participants, fundamentalist traders who buy when the asset price is below the fundamental value and sell when it is above and noise traders who use moving average technical trading rules that can lead them to chase trends. Agents switch from one type of strategy to the other according to relative returns. A variety of outcomes are studied using numerical simulation, including variation of market price responsiveness to changes in excess demand, in switching behavior, and the introduction of noise. Bifurcation analysis of certain parameters is presented.
\end{abstract}

Keywords: Emergent volatility; Heterogeneous agents; Complex dynamics; Moving average strategy

\section{INTRODUCTION}

Asset market price dynamics have been much studied, especially their unpredictable, and fluctuating nature marked by irregular switching from generally bull market dynamics to bear market dynamics and vice versa. The conventional efficient markets hypothesis argues that apparently erratic asset price dynamics reflect more-or-less random news. But, there has been concern regarding "excess volatility", namely, some price fluctuations may have exceeded what would be explained by rational fundamental value adjustment based on random news.

However, the conventional view is a more recent one, with an old tradition going back at least as far as the tulipmania of the 1630 s in the Netherlands suggesting that trend chasers can destabilize markets with speculative frenzies, with John Stuart Mill (1848) providing a classic version of this argument (Rosser, 2000, Chapter 4). However, the idea that speculation must be ultimately stabilizing because speculators must lose money and will go out of business also dates back to nearly the time

*Corresponding author. e-mail: hg.li@263.net

${ }^{\dagger} \mathrm{e}$-mail: rosserjb@jmu.edu 
of the tulipmania, with the Dutchman, Graswinckel (1651) providing the classic argument. Over the centuries the debate has gone back and forth. Friedman (1953) presented the classic argument that speculation in foreign exchange markets is stabilizing, arguably in response to earlier discussions of destabilization speculation by Keynes (1936). Baumol (1957) and Telser (1959) responded that heterogeneous agents and imperfect competition can undermine Friedman's argument. Friedman's argument was given its more sophisticated version about this time when Muth (1961) introduced the rational expectations hypothesis to explain why agricultural markets are relatively stable despite the possibility of lagged adjustment effects of the cobweb type. Muth's model did not address the issue of speculation or bubbles directly, but Tirole (1982) demonstrated that bubbles are impossible in a discrete-time world with a finite number of fully informed and rational, risk-averse, infinitely-lived agents who trade a finite number of real assets with real returns. In a stochastic world with rational expectations, market volatility should reflect the volatility of new information only.

Zeeman (1974) presented a catastrophe theory model showing how volatility could arise in a world with fundamentalist and trend-chasing chartist traders when chartist traders are a strong enough influence in the market. More recently, Black (1986) introduced the concept of noise traders. For example, Shiller (1989) argued that the crash of 1929 or the Black Monday of October 1987 was related to "internal dynamics of investor thinking". In classic discussions, DeLong, Shleifer, Summers and Waldmann $(1990,1991)$ showed that noise traders could survive and even do better than fundamentalist traders on some occasions. Day and Huang (1990) and DeGrauwe, Dewachter and Embrechts (1993) have shown that chaotic dynamics can arise in models with fundamentalists and chartists when the latter exercise sufficient influence. Others examining the dynamics of such heterogeneous agent models with complex dynamics in asset markets include Arthur, Holland,
LaBaron, Palmer, and Tayler (1997); Brock and Hommes (1998); Lux (1998) and Chiarella, Dieci, and Gardini (2000). A general result is that as market shares fluctuate between traders who are more fundamentalist and those that are more chartist, the nature of market dynamics likewise fluctuates.

In this paper we extend this line of analysis to a model with both fundamentalist and noise traders. The noise traders buy and sell according to the behavior of market price compared to a moving average, a well known strategy used by some "technical traders" in financial markets. Agents switch back and forth between strategies based on their relative performance. The model is studied through numerical simulation. A rapid price adjustment response to excess demand is found to increase market volatility and complexity of dynamics. Increasing the ease of switching behavior can lead to divergent outcomes, with convergence to the equilibrium if the switch is from noise traders to fundamentalists and possibly explosive behavior if the switch is in the opposite direction. Shortening the time horizon of the noise traders' moving average leads to more regularity of fluctuations. The impact of exogenous noise is examined. A bifurcation analysis of the speed of adjustment parameter is also undertaken. Our results confirm the widely held view that wider use of technical trading tends to induce greater irregularity and volatility in asset markets.

\section{THEORY OF MARKET PARTICIPANTS}

Instead of homogeneous, fully rational, wellinformed, and risk-averse agents, our model allows for heterogeneity among traders, namely, there exist at least two types of traders in the asset market. One is $F$-traders, who are fully rational and well- informed investors; the other is $\mathrm{N}$ traders, who are either less well-informed, irrational, or risk-loving (Delong, Shleifer, Summers and Waldmann, 1990). Our model is based on 
stylized representations of these two types of market participants who use different strategies.

F-traders may be referred to as an "fundamentalists" or "information traders". Let $x$ be the current market price of a unit of the asset and let $v$ be its fundamental value, which can be regarded as the present discounted value of the rationally expected stream of future net earnings of a unit of the asset. We suppose that the F-traders know the fundamental value $v$ statistically by means of rational and scientific estimate, e.g., so-called "fundamental analysis" based on sophisticated statistical analyses of trends in aggregate economic variables, industry aggregates, individual company performances, and so on. Obviously, the F-traders attempt to incorporate the most recent information into their estimates of $v$. As germane events may occur almost randomly, the fundamental value could be rather volatile.

In general, the current market price $x$ diverges from the fundamental value $v$. The $F$-traders think this means temporary "false pricing", and believe $x$ and $v$ will converge in the long run. If $x$ is below $v$ now the $F$-traders expect to obtain a capital gain in the future, so they will try to enter the market and buy units of the asset. On the contrary, if $x$ is above $v$ the $F$-traders expect a capital loss, so they will attempt to sell units of the asset and exit the market. Furthermore, the F-traders' decision to buy or sell shares depends on the divergence between $x$ and $v$. If the spread is strongly positive, the opportunity for a capital gain and desire for the asset is great; while if it is strongly negative the risk of a capital loss and rejection of the asset is great. That is to say, the greater spread, the more desire for trade. Therefore the $F$-traders' trading strategy is given as by a simple excess demand function:

$$
e f_{t}=c_{F}\left(v_{t}-x_{t}\right)^{3}=\left(v_{t}-x_{t}\right)^{3}, v_{t}=v_{t-1}+h \varepsilon_{t}
$$

with the nonnegative parameter $c_{F}$ measuring the $F$-traders' excess demand response to a price gap. For simplicity, let $c_{F}=1$. We assume that $\varepsilon_{t}$ is a standard Guassian white noise, which implies that $v_{t}$ is a random walk.
$N$-traders may be referred to as "Non-fundamentalists" or "Noise traders". The F-traders' trade strategy is based on estimating the fundamental value $v$. But, evaluating the fundamental value $v$ is costly. Many market participants cannot afford to pursue this behavior; they do not act as F-traders but as $N$-traders and instead use relatively simple and low cost rules, so-called "technical analysis". One of the simplest and most widely used technical rules is a moving average rule.

According to such a rule, buy and sell signals are generated by two moving averages of the level of the index: a long-period average and a short-period average. In its simplest form this strategy is expressed as buying (or selling) when the short-period moving average rises above (or falls below) the longperiod moving average. This means the $N$-traders chase prices up and down. The idea behind computing a moving average is to smooth out an otherwise volatile series. When the short-period moving average penetrates the long-period moving average, the $N$-traders think a trend to be initiated and capital gain or loss to be expected. By comparison with $F$-traders, the $N$-traders neither know the fundamental value $v$ nor believe the current market price $x$ and $v$ will converge in the long run. Indeed, although they are generally characterized as irrational or poorly informed, we remind that DeLong, Shleifer, Summers, and Waldmann (1991) demonstrated that noise traders can sometimes do better than all other market participants, especially when their behavior is driving the market outcomes.

Here we adopt one of the simplest rules: the short-period moving average is just the current market price $x$ and the long-period one is just an exponentially weighted moving average, which is also an adaptive expectation of current price $x$. Let $y$ denote the long-period moving average. Consequently, the $N$-traders' trade strategy can also be given as a simplified expression by an excess demand function:

$$
\begin{gathered}
e n_{t}=c_{N}\left(x_{t}-y_{t}\right)=x_{t}-y_{t} \\
y_{t}=\alpha x_{t-1}+(1-\alpha) y_{t-1} \quad \alpha \in[0,1]
\end{gathered}
$$


with the nonnegative parameter $c_{N}$ measuring the $N$-traders' excess demand response to a price change. For simplicity, let $c_{N}=1$. The parameter $\alpha$ dominates the weight distribution for the longperiod average, and the bigger value is, the shorter is the effective period of the moving average.

\section{THE DYNAMIC EQUATION OF MARKET PRICES}

Suppose that the total F-traders and N-traders equal one, and the F-traders' share is $w$, then the aggregate excess demand of the whole market is

$$
e_{t}=w_{t} e f_{t}+\left(1-w_{t}\right) e n_{t}
$$

where a positive $e$ means that demand exceeds supply and a negative $e$ means supply exceeds demand.

We suppose that there exists a market-maker who mediates the trading in the market. The market-maker helps to meet the excess demand and adjusts the next period market price depending on the excess demand. Generally, we can assume that the change in market price is determined by a continuous, monotonically increasing function of aggregate excess demand $e$. We model the dynamic adjustment of market price by the following difference equation:

$$
x_{t+1}-x_{t}=b e_{t}=b w_{t} e f_{t}+b\left(1-w_{t}\right) e n_{t}
$$

with the nonnegative parameter $b$ measuring price adjustment flexibility.

As the market price changes, the share of the two types of investors evolves. We assume that the type changes on the basis of the past relative performance of the two trade strategies. If Ftraders earn a higher return than $\mathrm{N}$-traders in past $k$ periods, a fraction of $\mathrm{N}$-traders will become $\mathrm{F}$ traders, and vice versa if F-traders earn a lower return. Moreover, the higher the difference in realized past returns, the more people will switch. Let $R$ be the past relative return of the two trade strategies, we suppose that the share of the two types of investors evolves according to a logistic pattern:

$$
w_{t+1}=\frac{w_{t}}{w_{t}+\left(1-w_{t}\right) e^{-g R_{t}}}
$$

where $g$ is a measure of type switch sensitivity based on the relative past returns, and we suppose that the relatives past return of the two trade strategies during the past $k$ periods is:

$$
\begin{aligned}
R_{t}= & {\left[x_{t} \sum_{j=t-k}^{t-1} e f_{j}-\sum_{j=t-k}^{t-1} x_{j} e f_{j}\right] / k } \\
& -\left[x_{t} \sum_{j=t-k}^{t-1} e n_{j}-\sum_{j=t-k}^{t-1} x_{j} e n_{j}\right] / k
\end{aligned}
$$

\section{NUMERICAL SIMULATION OF THE PRICE DYNAMICS}

Equations (1) to (7) constitute our basic model of asset market dynamics, and it is easy to examine its dynamical behavior by numerical simulation. Here we present some simulation results for different parameter values, from which we can see how some important factors affect the dynamical behavior of market price.

\subsection{Market Price Adjustment Flexibility (b)}

Intuitively, market price adjustment flexibility has great effect on the price dynamic behavior. As Figures 1 to 4 show, as the adjustment flexibility increases, the market price fluctuates more erratically. When $b$ is small, the price dynamic curve is almost in a steady state (see Fig. 1). But as $b$ grows, the price time series begins to follow a regular limit cycle around the fundamental value (see Fig. 2). When $b$ achieves some value, there appear more irregular secondary fluctuations on the regular cycle, especially on its turning parts (Fig. 3), which may describe the critical price behavior resulting from the different type traders' 


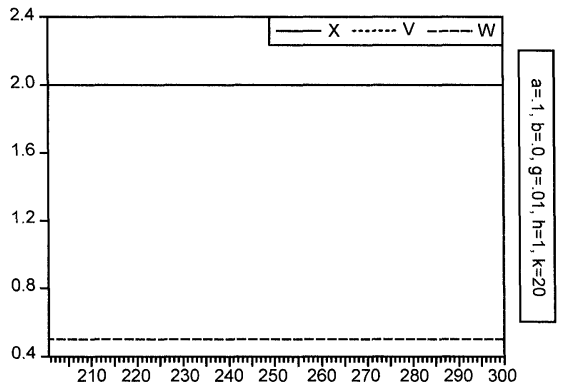

FIGURE 1 Price dynamics, low market price flexibility.

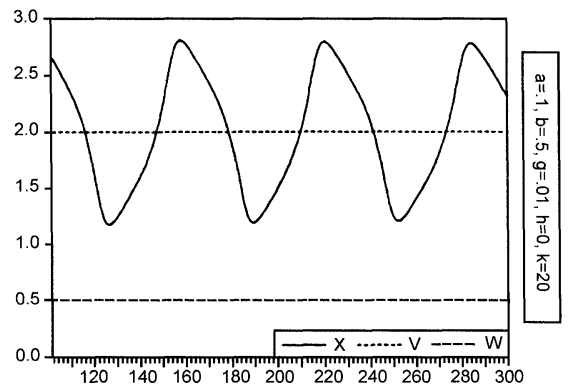

FIGURE 2 Price dynamics, moderate market price flexibility.

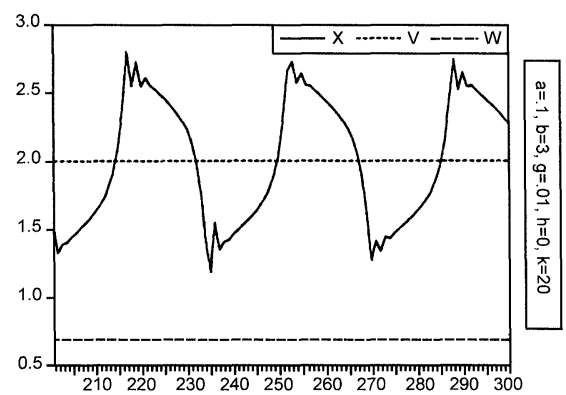

FIGURE 3 Price dynamics, moderately high market price flexibility.



FIGURE 4a Distribution of price changes, very high market price flexibility.

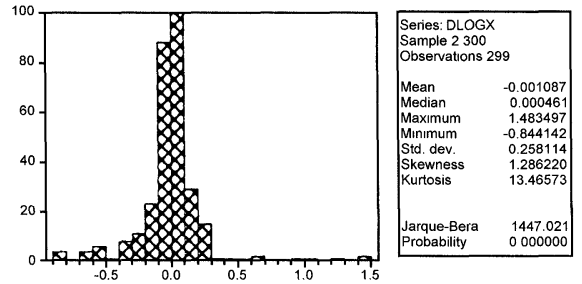

FIGURE $4 \mathrm{~b}$ Distribution of price change rates, very high market price flexibility.

battle with each other. This is a nonlinear phenomenon that stems from our nonlinear model, and it presents some apparent local randomness not due to exogenous random noise. A sufficiently large $b$ may break the cycle pattern and cause completely irregular price changes (Fig. 4), which may resemble randomness, but without exogenous random noise, an apparently chaotic pattern. The Figures $4 a$ and $b$ show the distribution of the price and price change rate in Figure 4, the former is a double-peak distribution and the latter is a single-peak distribution.

\subsection{Type Switch Sensitivity Based on the Relative Past Performances ( $g$ )}

The $g$ denotes the type switch sensitivity based on the relative past performance, and the bigger the $g$ is, the more type switch happens. This means that $g$ controls change pace of change of the shares of the two kinds of traders. In general, we can regard the F-traders as market stabilizing and regard the $\mathrm{N}$-traders as market destabilizing. More Ftraders keep the price less volatile and vice versa. Obviously, the relationship of the type switch sensitivity and the price volatility depends on type switch direction. If the switch is from F-traders to $\mathrm{N}$-traders, a big $g$ will speed up the growth of the destabilizing factor and result in greater market price fluctuation, and vice versa.

Figures 3 and 4 show the price dynamic series for different values of $g$. In the two cases, the switch just happens from $\mathrm{N}$-traders to $\mathrm{F}$-traders, and the F-traders in Figure 3 case have a larger share than do the F-traders in Figure 4. We can 
expect that, if the type switch is too sensitive to the relative past performance, the market will soon be dominated by one type of traders. In case the F-traders dominate the market, the price will eventually converge to fundamental value. But in case the $\mathrm{N}$-traders dominate the market, the price may eventually explode.

\subsection{Moving Average Period (a)}

The parameter $a$ reflects the $\mathrm{N}$-traders' moving average period, and the big parameter value implies the short period of the moving average. The shorter the moving average period is, the sooner the $\mathrm{N}$-traders react to the market price change. Is the rapid reaction beneficial or harmful to market stability? Intuitively, it might appear that the rapid reaction would tend to destabilize the market price dynamics. But Figures 5 and 6 suggest a different result. Figure 5 exhibits a regular limit cycle fluctuation.

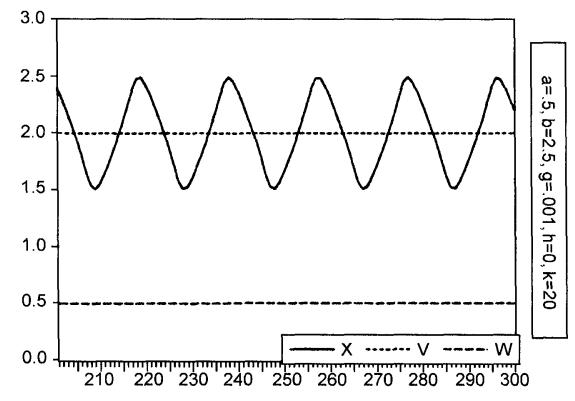

FIGURE 5 Price dynamics, short moving average period adjustment.



FIGURE 6 Price dynamics, long moving average period adjustment.
In contrast, Figure 6 exhibits an irregular bubblelike price evolution, and we can regard it as less stable. In general, the former has greater stability than the latter. When the moving average period is short, the N-traders' trade strategy has better adaptability to market changes and eliminates the accumulation of destabilizing effects more quickly. This suggests that we might have a tradeoff between more but regular fluctuations and fewer but more erratic variations of the market price.

\subsection{Evaluation Horizon of Past Relative Performance of the Two Trade Strategies $(k)$}

We have assumed that the traders type changes on the basis of the past relative performance of the two trade strategies, and this makes it important how long is the evaluation horizon of the past. Intuitively, we can guess that the F-traders will on average have better relative performance than the $\mathrm{N}$-traders within a long time horizon. Figures 7 and 8 confirm this conjecture. In Figure 7 case, the evaluation horizon is so long that the F-traders strategy gets more return then $\mathrm{N}$-traders strategy, then the share of F-traders increases and the market price converge to the fundamental value gradually. Moreover, in Figure 8 the evaluation horizon is short, then the $\mathrm{N}$-traders' evaluation horizon is so long that the F-traders' strategy gets more return than the $\mathrm{N}$-traders' strategy. Then the share of F-traders increases and the market price converges to the fundamental value gradually. However, if the evaluation horizon is sufficiently

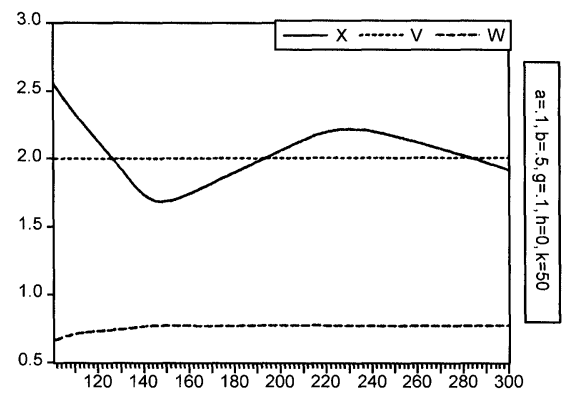

FIGURE 7 F-traders versus $\mathrm{N}$-traders, long evaluation horizon. 


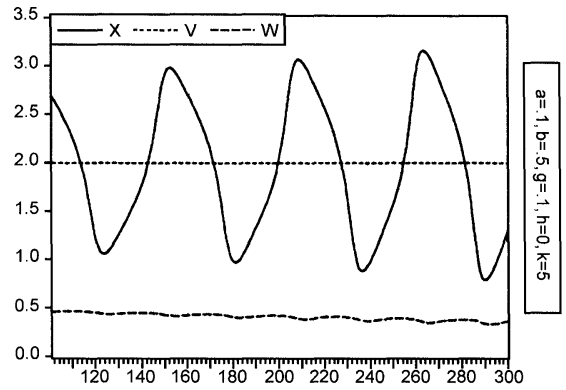

FIGURE 8 F-traders versus $\mathrm{N}$-traders, short evaluation horizon.

short, then the $\mathrm{N}$-traders have the have better performance, and they dominate the market gradually, this may cause the market price to explode eventually. This result is different from Friedman's argument (1953) who claimed that the $\mathrm{N}$-traders would be a final loser and disappear from the market eventually. Beside these two kind of cases, we can expect there may exist a certain time horizon that neither trade strategy has an advantage and the share of two type traders keeps constant or fluctuates.

\subsection{Noise Effect $(h)$}

Certainly, a more realistic asset price dynamic model should consider the effect of exogenous random noise as well. Figures 9 to 12 are respectively Figures 1 to 4 with white noise added. As we can see, the noise changes greatly the dynamic behavior of market price, and this makes the price curves seem more realistic compared with

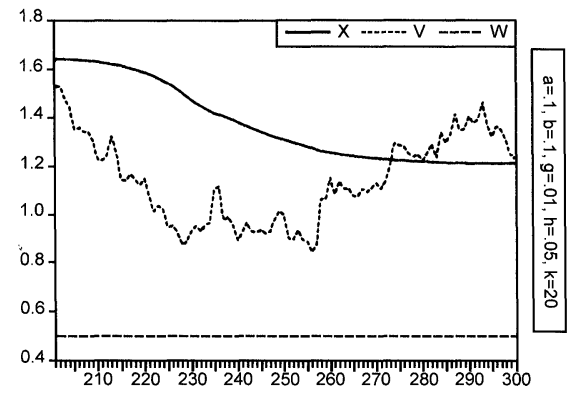

FIGURE 9 Low market price flexibility with exogenous noise.

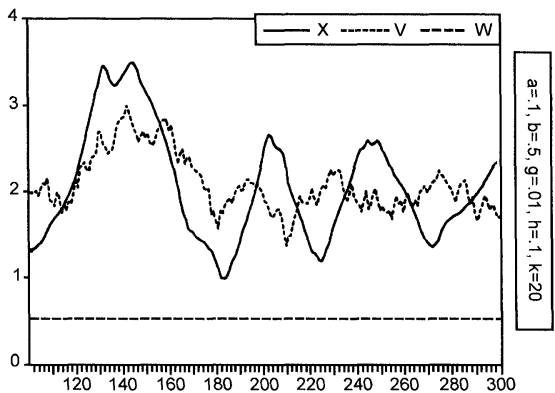

FIGURE 10 Moderate market price flexibility with exogenous noise.



FIGURE 11 Moderately high market price flexibility with exogenous noise.

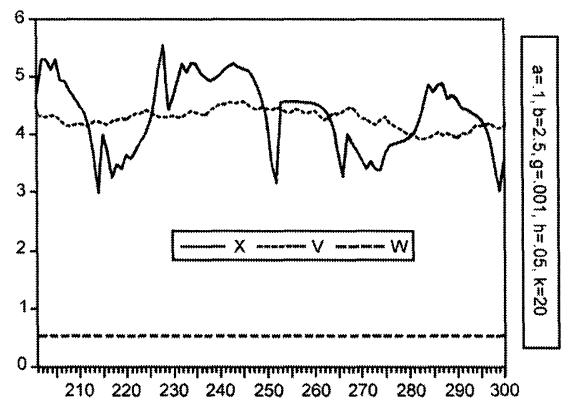

FIGURE 12 Very high market price flexibility with exogenous noise.

the respective curves without noise. Although the price movement can exhibit some apparent randomness without exogenous noise, the noise generally strengthens the market randomness. Moreover, as a nonlinear system, the noise volatility of the fundamental value is not just transferred to final market price, but may be absorbed in some cases (see Fig. 9) or amplified in 
other cases (see Fig. 11). If we think the fluctuation stemming from nonlinear dynamic system as intrinsic randomness, and the noise volatility as exogenous randomness, then their interaction will generate a more complex randomness, which may be more close to real complex dynamic system such as asset market.

\section{BIFURCATION ANALYSIS}

\subsection{Price Flexibility Parameter (b)}

Figure 13 exhibits a bifurcation diagram showing the pattern for the behavior of $x$ as $b$ is varied, the parameter of the flexibility of price adjustment. As seen in Figures 1-4, it is clear that variations in $b$ are associated with qualitative changes in the dynamic behavior of the system. The pattern of the values of $b$ associated with bifurcations of the system's dynamic structure is presented in Figure 13. It follows a classic pattern that has been seen in many dynamical systems, with a single stable equilibrium for low values, followed by a series of bifurcations as $b$ increases. This is consistent with the pattern shown in Figures 14. However, we note that we have not engaged in any tests to demonstrate the presence or absence of any particular form of mathematical chaos in the dynamic patterns, although this is quite likely.



FIGURE 13 Market price flexibility and bifurcation of price behavior.

\subsection{Switching Parameter (g)}

Figure 14 shows a bifurcation analysis of the behavior of $w$ as a function of $g$. $W$ is the share of the traders who are fundamentalists. $G$ is the sensitivity to switching from one type of trader to another. Previous literature (Brock and Hommes, 1998) suggests that this parameter, or something like it, is likely to be involved in qualitative changes in dynamic behavior of financial markets. This figure shows that as the switching parameter rises above a certain critical value, there is a tendency for the system to go to all one type of trader or the other, with explosive behavior tending to result when all the traders become $\mathrm{N}$ traders. This outcome differs from that of Brock and Hommes and some others in that we do not have a countervailing mechanism that, for example, will induce traders to become fundamentalists if most others are noise traders in an exploding market. Such mechanisms can induce a variety of complex dynamics, as has been shown by Brock and Hommes and others.

\subsection{Moving Average Period (a)}

Figure 15 presents the bifurcation analysis results for variations of the moving average period parameter, $a$. As can be seen reductions of the parameter, $a$, lead to a destabilization and sequence of bifurcations that may end in chaotic dynamics. It should be kept in mind here that a

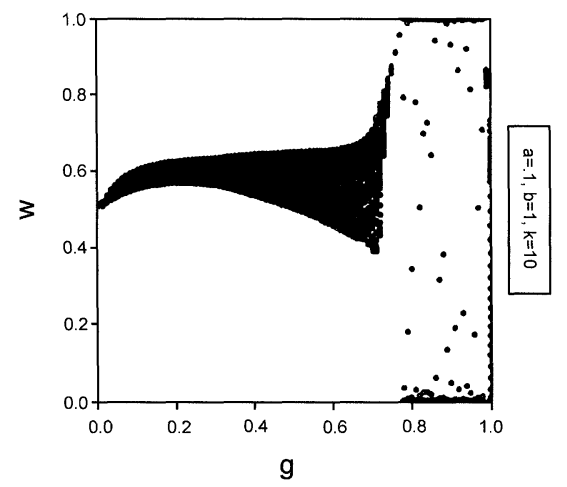

FIGURE 14 Switching sensitivity and bifurcation of shares behavior. 




FIGURE 15 Moving average length and bifurcation of price behavior.

lower a means a longer time horizon that is used for estimating the moving average that determines the behavior of the $\mathrm{N}$-traders. A more rapid adjustment by the noise traders is thus more stabilizing.

\section{CONCLUSIONS}

We have studied the behavior of a model of asset market dynamics with two types of traders. One are fundamentalists who are able to determine the long term fundamental value of the asset being traded. Another are non-fundamentalists or noise traders who base their buying and selling behavior on the relationship between a moving average of past prices and the current price. Complex dynamics and greater volatility are seen to emerge as certain parameters in the system are varied. In particular, the speed of adjustment of price to excess demand is found to be a parameter that is associated with the emergence of volatility and complexity. Also, if switching between trader types becomes too sensitive, there is a tendency for the system to become dominated by one type or the other. Also, a longer time horizon of the moving average that drives the noise trader behavior is seen to induce more complex dynamics. In effect, this means that the longer the trends that the noise traders chase, the more likely it will be that the system will exhibit complex and highly volatile dynamics. Adding noise to the system further complicates the dynamics, although not in any particularly systematic manner.

This study thus confirms the results that asset market dynamics with heterogeneous agents can exhibit greater volatility and more complexity of dynamics than do models with homogeneous agents who possess rational expectations.

\section{References}

Arthur, W. B., Holland, J. H., LeBaron, B., Palmer, R. and Tayler, P. (1997) Asset Pricing Under Endogenous Expectations in an Artificial Stock Market. In: The Economy as an Evolving Complex System II (Arthur, W. B., Durlauf, S. N. and Lane, D. A. Eds.) Addison-Wesley, Reading, pp. 15-44.

Baumol, W. J. (1957) Speculation, Profitability, and Stability. Review of Economics and Statistics, 39, 263-271.

Black, F. (1986) Noise. Journal of Finance, 41, 529-543.

Brock, W. A. and Hommes, C. H. (1998) Heterogeneous Beliefs and Routes to Chaos in a Simple Asset Pricing Model. Journal of Economic Dynamics and Control, 22, 1235-1274.

Chiarella, C., Dieci, R. and Gardini, L. (2000) Asset Price Dynamics in a Financial Market with Fundamentalists and Chartists. Mimeo. University of Technology-Sydney, University of Parma, and University of Urbino.

Day, R. H. and Huang, W. (1990) Bulls, Bears, and Market Sheep. Journal of Economic Behavior and Organization, 14, 299-329.

De Grauwe, P., Dewachter, H. and Embrechts, M. (1993) Exchange Rate Theory: Chaotic Models of Foreign Exchange Rates. Blackwell, Oxford.

DeLong, J. B., Shleifer, A., Summers, L. H. and Waldmann, R. J. (1990) Positive feedback investment strategies and destabilizing rational speculation. Journal of Finance, 45, 379-395.

DeLong, J. B., Shleifer, A., Summers, L. H. and Waldmann, R. J. (1991) The Survival of Noise 'Traders in Financial Markets. Journal of Business, 64, 1-19.

Friedman, M. (1953) The Case for Flexible Exchange Rates. In: Essays in Positive Economics. University of Chicago Press, Chicago, pp. 157-203.

Graswinckel, D. (1651) Placaetbook op het stuk van de Leeflocht [Compilation of Regulations Concerning Food]. Amsterdam.

Keynes, J. M. (1936) The General Theory of Employment, Interest and Money. Macmillan, London.

Lux, T. (1998) The Socio-Economic Dynamics of Speculative Markets: Interacting Agents, Chaos, and the Fat-Tailed Distribution of Returns. Journal of Economic Behavior and Organization, 33, $141-165$.

Mill, J. S. (1848). Principles of Political Economy. Parker, London.

Muth, J. T. (1961) Rational Expectations and the Theory of Price Movements. Econometrica, 19, 315-335.

Rosser, J. B. Jr. (2000) From Catastrophe to Chaos: A General Theory of Economic Discontinuities, I: Mathematics, Microeconomics, Macroeconomics, and Finance. Kluwer Academic Publishers, Boston/Dordrecht. 
Shiller, R. (1989) Market Volatility. MIT Press, Cambridge, MA.

Telser, L. G. (1959) A Theory of Speculation Relating Profitability and Stability. Review of Economics and Statistics, 41, 295-301.
Tirole, J. (1982) On the Possibility of Speculation under Rational Expectations. Econometrica, 50, 1163-1181.

Zeeman, E. C. (1974) On the Unstable Behavior of the Stock Exchanges. Journal of Mathematical Economics, 1, 39-44. 


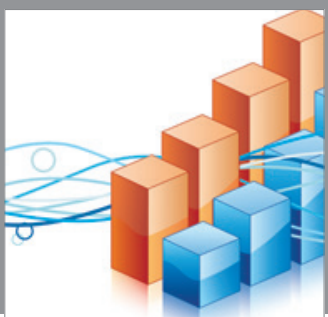

Advances in

Operations Research



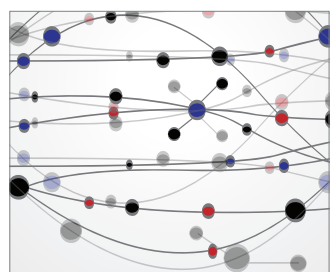

\section{The Scientific} World Journal
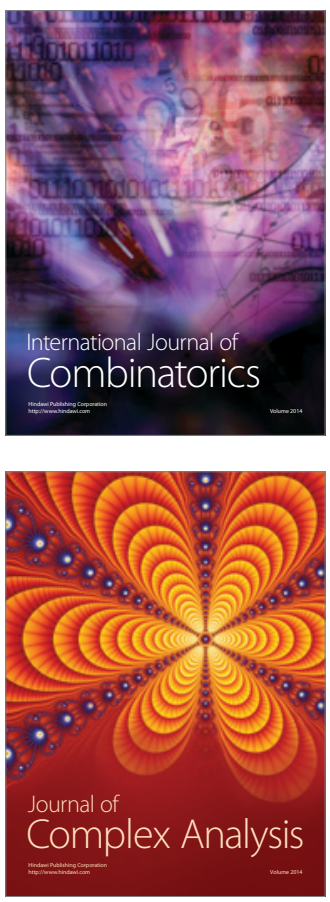

International Journal of

Mathematics and

Mathematical

Sciences
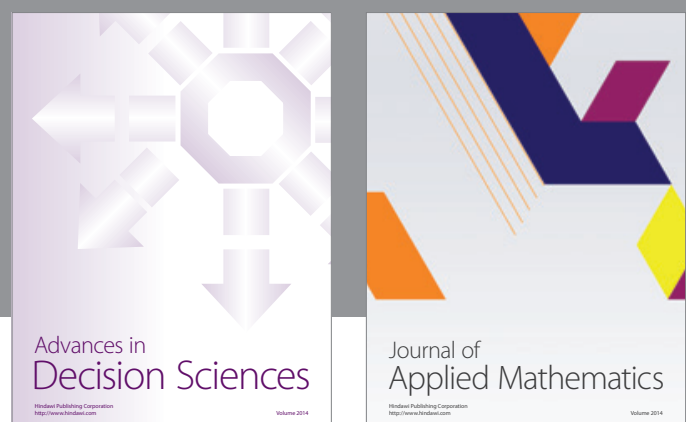

Journal of

Applied Mathematics


Submit your manuscripts at http://www.hindawi.com
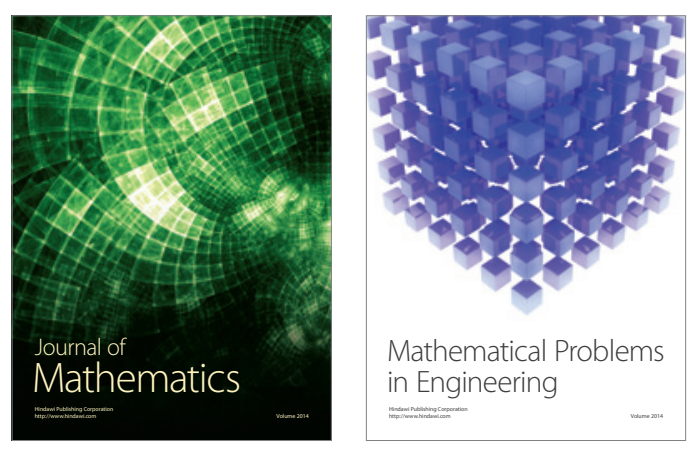

Mathematical Problems in Engineering
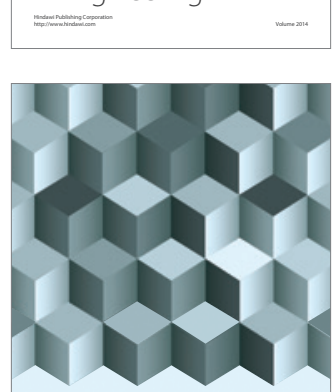

Journal of

Function Spaces
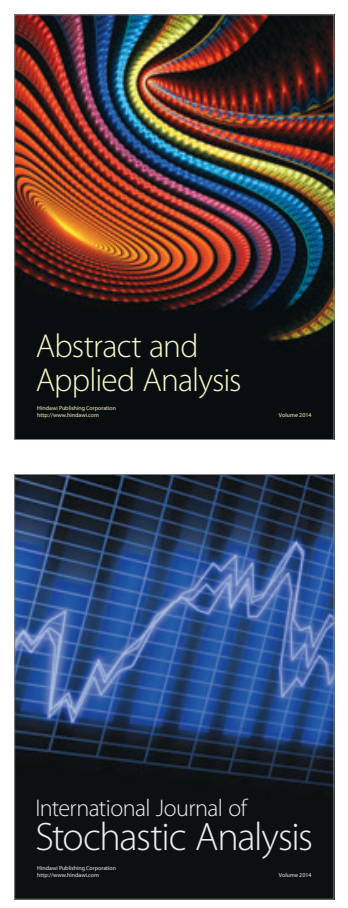

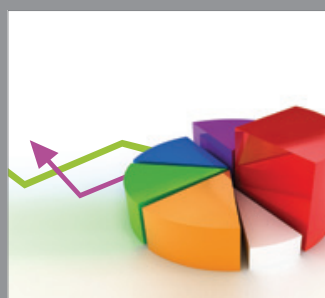

ournal of

Probability and Statistics

Promensencen
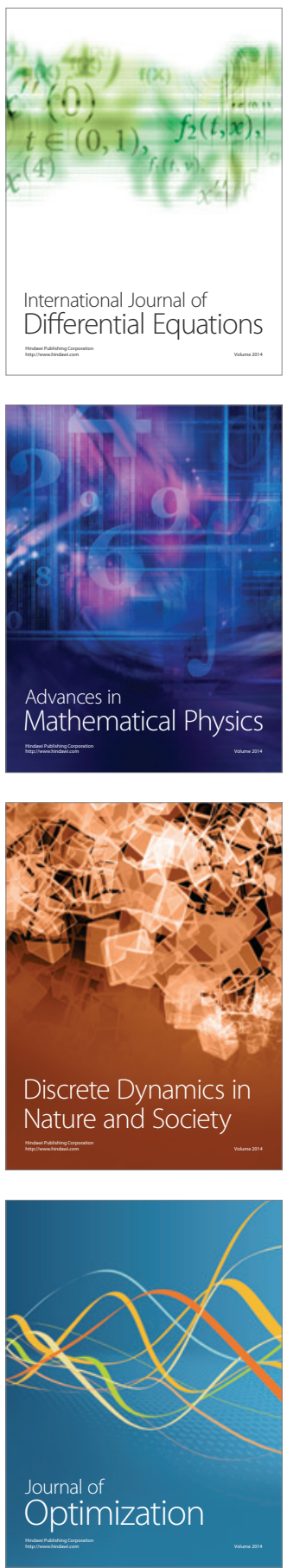